Check for updates

New York

Cite this as: $B M J 2021 ; 375: \mathrm{n} 2834$ http://dx.doi.org/10.1136/bmi.n2834 Published: 18 November 2021

\section{Covid 19: US government committee hears how social media spreads misinformation}

\author{
Janice Hopkins Tanne
}

Americans are endangered by misinformation about the covid-19 pandemic and promotion of false treatments on social media, with platforms not doing enough to control falsehoods, the chair of a US representatives committee has warned.

James Clyburn, chair of the House of Representatives Select Subcommittee on the Coronavirus Crisis opened a hearing on 17 November saying, "Since the pandemic began, Americans have been targeted by an unprecedented level of misinformation about the coronavirus. Bad actors have promoted false and even dangerous products as treatments and have pushed lies disputing the safety and effectiveness of vaccines. Coronavirus misinformation spreads wildly online, including on social networks like Facebook, Twitter, and YouTube."

The subcommittee is conducting an inquiry into the harm caused by the spread and monetisation of coronavirus misinformation online to try and identify the steps needed to stop the spread and promote accurate public health information.

Clyburn, a South Carolina Democrat, said that social media platforms have not done enough to stop the spread of misinformation. Americans have wasted millions of dollars on fake and hazardous treatments, false vaccination cards, and false religious or medical exemptions from vaccination. "By feeding the American public falsehoods about the virus, vaccines, and treatments, these bad actors on social media make it harder to distinguish between legitimate and illegitimate sources of health information-and harder to know how to protect ourselves and our loved ones," he said.

Just days earlier the subcommittee released documents showing how the administration of former president Donald Trump had tried to block or change information about the pandemic from officials from the Centers for Disease Control and Prevention (CDC).

Jay Kennedy, of the School of Criminal Justice and the Center for Anti-Counterfeiting and Product Protection at Michigan State University, told the hearing, "The epidemic created an opportunity for fraud.” He called for public and private partnerships to combat misinformation because "people are searching for things that make them feel safe."

Jeffrey Aeschlimann, of the School of Pharmacy and the School of Medicine at the University of Connecticut, said he had seen how people were harmed. He described an unvaccinated man who took ivermectin and hydroxychloroquine. The man became severely ill with covid-19 was in hospital for a week. "This could have been prevented," he said.
Jay Bhattacharya, a professor at Stanford University Medical School, disagreed with the US approach of widespread vaccination and lockdowns of schools, which he said had a devastating effect on public health. He suggested the approach advocated by the Great Barrington Declaration-that the vulnerable elderly should be protected, but children should be allowed to go to school and others should go about their lives until herd immunity was achieved through natural infections and vaccinations. ${ }^{2}$

Maria Teresa Kumar, president of Voto Latino, said that Latinos were subjected to misinformation from domestic and foreign sources and suffered unusually high rates of illness and deaths from the pandemic. She said they didn't trust scientific sources, doctors, and the government but would be more receptive to "honest conversations" with trusted people in their communities, such as pastors.

Republican representative Steve Scalise of Louisiana challenged the government's research and approach to the pandemic. He said that the National Institutes of Health should have done more research on alternative therapies such as hydroxychloroquine.

Last week the committee revealed documents showing that Trump administration officials had tried to block scientific information about the pandemic.

It cited the case of Nancy Messonnier, a CDC official who said that spread of the virus was inevitable. President Trump was so angered that he stopped CDC officials from speaking to the public. It also noted that Trump had forced the CDC to water down its recommendations for testing, and that he had pressured officials to approve hydroxychloroquine for emergency use. Federal officials had also tried to have the CDC alter reports in the Morbidity and Mortality Weekly Report to be in line with more rosy White House views on the pandemic. ${ }^{3}$

\footnotetext{
Hearing: Combating coronavirus cons and the monetization of misinformation. 2021. https://youtu.be/eNsdwjYc3cA.

This article is made freely available for use in accordance with BMJ's website terms and conditions for the duration of the covid-19 pandemic or until otherwise determined by BMJ. You may use, download and print the article for any lawful, non-commercial purpose (including text and data mining) provided that all copyright notices and trade marks are retained.
} 